\title{
In Vitro N-Glycan Mannosyl-Phosphorylation of a Therapeutic Enzyme by Using Recombinant Mnn 14 Produced from Pichia pastoris
}

\author{
Ji-Yeon Kang ${ }^{1}$, Hong-Yeol Choi ${ }^{2}$, Dong-Il Kim ${ }^{2}$, Ohsuk Kwon ${ }^{1,3 *}$, and Doo-Byoung Oh ${ }^{1,3 *}$ \\ ${ }^{1}$ Korea Research Institute of Bioscience and Biotechnology (KRIBB), Daejeon 34141, Republic of Korea \\ ${ }^{2}$ Department of Biological Engineering, Inha University, Incheon 22212, Republic of Korea \\ ${ }^{3}$ Biosystems and Bioengineering Program, University of Science and Technology (UST), Daejeon 34113, Republic of Korea
}

\begin{abstract}
Enzyme replacement therapy for lysosomal storage diseases usually requires recombinant enzymes containing mannose-6-phosphate (M6P) glycans for cellular uptake and lysosomal targeting. For the first time, a strategy is established here for the in vitro mannosyl-phosphorylation of high-mannose type $\mathrm{N}$-glycans that utilizes a recombinant $\mathrm{Mnn} 14$ protein derived from Saccharomyces cerevisiae. Among a series of $\mathrm{N}$-terminal- or C-terminal-deleted recombinant Mnn14 proteins expressed in Pichia pastoris, $\mathrm{rMnn} 14_{77-935}$ with deletion of $\mathrm{N}$-terminal 76 amino acids spanning the transmembrane domain ( 46 amino acids) and part of the stem region ( 30 amino acids), showed the highest level of mannosyl-phosphorylation activity. The optimum reaction conditions for $\mathrm{rMnn} \mathbf{1 4}_{77-935}$ were determined through enzyme assays with a high-mannose type $\mathrm{N}$-glycan ( $\mathrm{Man}_{8} \mathrm{GICNAc}_{2}$ ) as a substrate. In addition, rMnn $14_{77-935}$ was shown to mannosyl-phosphorylate high-mannose type $\mathrm{N}$ glycans $\left(\right.$ Man $_{7-9} \mathrm{GlcNAC}_{2}$ ) on recombinant human lysosomal alpha-glucosidase (rhGAA) with remarkably high efficiency. Moreover, the majority of the resulting mannosyl-phosphorylated glycans were bis-form which can be converted to bis-phosphorylated M6P glycans having a superior lysosomal targeting capability. An in vitro $\mathrm{N}$-glycan mannosyl-phosphorylation reaction using rMnn 14 ${ }_{77-935}$ will provide a flexible and straightforward method to increase the M6P glycan content for the generation of "Biobetter" therapeutic enzymes.
\end{abstract}

Keywords: Mannosyl-phosphorylation, Mannose-6-phosphate, Mnn14, enzyme replacement therapy, lysosomal storage disease

Received: October 14, 2020 Accepted: October 22, 2020 First published online: October 28, 2020

*Corresponding authors D-B.Oh

Phone : +82-42-860-4459 Fax : +42-860-4549 E-mail: dboh@kribb.re.kr O.Kwon

Phone : +82-42-860-4457 Fax : +42-860-4549 E-mail: oskwon@kribb.re.kr

Supplementary data for this paper are available on-line only at http://jmb.or.kr.

pISSN 1017-7825 eISSN 1738-8872

Copyright(C) 2021 by The Korean Society for Microbiology and Biotechnology

\section{Introduction}

Lysosomal storage diseases (LSDs), a group of inherited diseases, are caused by hydrolase deficiency, which results in the accumulation of undigested metabolites in the lysosome. Enzyme replacement therapy (ERT) with an intravenous injection of a therapeutic recombinant enzyme is the prevalent option for treating LSDs [1]. Most therapeutic enzymes, except for those associated with Gaucher disease, require mannose-6-phosphate (M6P) glycans for efficient lysosomal targeting [1-3]. In the mammalian Golgi apparatus, M6P glycans are generated by a two-step process (Fig. 1A) [1]. First, GlcNAc-1-phosphotransferase adds GlcNAc-1-phosphate to the mannose residue of high-mannose type glycans. Then, the uncovering enzyme removes the outer GlcNAc to expose a phosphate group linked to the mannose residue, resulting in phosphate-6-O-mannose structure called M6P. Lysosomal enzymes containing M6P glycans are recognized by M6P receptors (MPRs) on the Golgi membrane. The resulting MPR-enzyme complexes are delivered to endosomes. As endosome maturation accompanies the decrease in the $\mathrm{pH}$ level, lysosomal enzymes are released from MPRs and go alone to the lysosome. Some enzymes escaping from this MPR pathway are secreted into the extracellular space. These secreted enzymes can be recaptured by the MPRs on the plasma membrane and delivered to the lysosome through MPR-mediated endocytosis. ERTs exploit this "MPR-based recapture pathway" for the cellular uptake and lysosomal targeting of infused therapeutic enzymes.

Because the M6P glycan content is a key factor determining the therapeutic efficacy of ERTs, glyco-engineering strategies for increasing the M6P glycan content have been designed to produce "Biobetter" enzymes for LSDs [1]. First, a strategy to conjugate synthetic M6P glycans to recombinant therapeutic enzymes was developed and successfully employed for recombinant human lysosomal alpha-glucosidase (rhGAA, brand name "Myozyme") for the treatment of Pompe disease. Conjugation of synthetic M6P glycans to rhGAA increased its binding affinity 
A

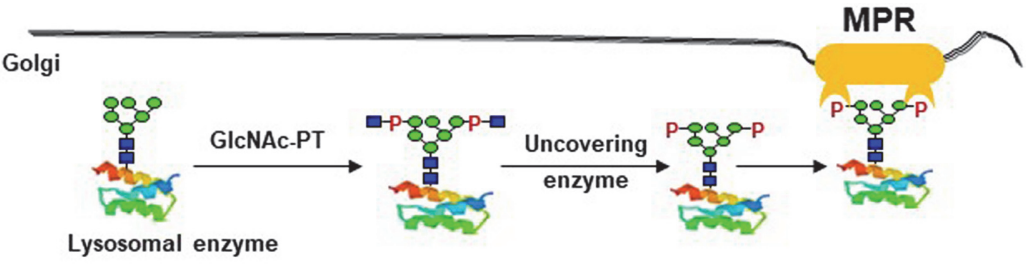

B

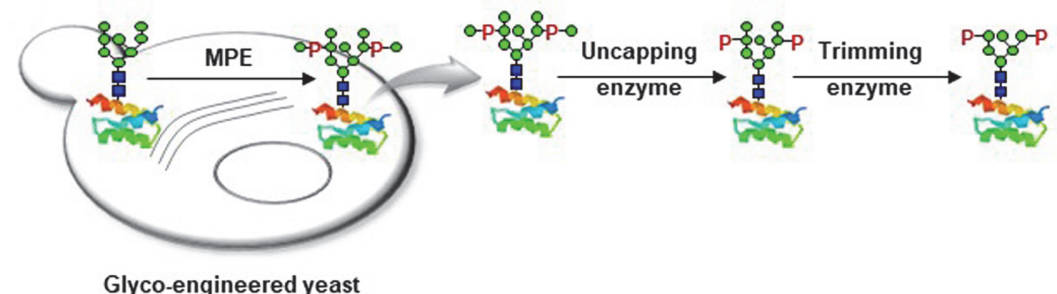

Fig. 1. Schematic representations of M6P glycan generations. (A) In mammalian Golgi, GlcNAc-1-phosphotransferase recognizes lysosomal enzymes and transfers the GlcNAc-1-phosphate moiety of UDP-GlcNAc to the mannose residues of the high-mannose type $\mathrm{N}$-glycans on enzymes. Then, an uncovering enzyme removes the outer GlcNAc to leave a phosphate group linked to a mannose residue. The resulting M6P glycans are recognized by MPRs on the Golgi membrane for traffic to the lysosome. (B) Recombinant proteins containing a large amount of mannosyl-phosphorylated glycans can be produced in glyco-engineered yeast overexpressing MPEs. The mannosyl-phosphorylated glycans on the secreted proteins can be uncapped and trimmed in vitro by using an uncapping enzyme and a trimming mannosidase, which generates M6P glycans for MPR targeting. Monosaccharide symbols follow the Symbol Nomenclature for Glycans(SNFG) system, details of which are found at NCBI: green circle, mannose; blue square, GlcNAc; P, phosphate [7].

to MPRs and therefore improved the therapeutic efficacy significantly in a Pompe disease mouse model [4-6]. Second, a strategy involving the heterologous expression of target therapeutic enzymes having mannosylphosphorylated glycans and subsequent in vitro enzymatic uncapping and trimming reactions has been established [3]. rhGAA containing mannosyl-phosphorylated glycans was expressed in a glyco-engineered yeast strain by deletion of its yeast-specific hyper-mannosylation pathway gene and introduction of a mannosylphosphorylation enzyme (MPE) gene (Fig. 1B). After secretory expression in this yeast, the mannosylphosphorylated glycans of rhGAA were converted to M6P glycans through in vitro uncapping and trimming reactions [3].

Mnn14 and YlMpo1 have been found to be the main MPEs in Saccharomyces cerevisiae and Yarrowia lipolytica, respectively, in our recent study involving gene disruptions and complementation experiments [7, 8]. If a recombinant MPE is available for an in vitro reaction, it will allow the development of another strategy to produce a "Biobetter" enzyme with a high content of M6P glycans through a combination of mannosyl-phosphorylation, uncapping, and trimming reactions. Here, for the first time, we report the production of a soluble recombinant MPE capable of adding mannosyl-phosphate efficiently to the high-mannose type $\mathrm{N}$-glycans of a therapeutic enzyme.

\section{Materials and Methods}

\section{Construction of Expression Vectors}

The microbial strains and plasmids used in this study are listed in Table S1. To construct vectors expressing recombinant MPEs, the corresponding DNA fragments of Mnn14 and YlMpol genes were amplified by polymerase chain reaction (PCR) using pYEp352-Mnn14 [8] and pYEp352-YlMpo1 [7] as templates, respectively, with primers (Table S2). The PCR products were cloned into the pPIZaA vector using EZ-Fusion cloning kits (Enzynomics, Korea) and were propagated in Escherichia coli DH5 $\alpha$.

\section{Secretory Expressions in P. pastoris}

The recombinant expression vectors were transformed into the P. pastoris PPS9016 strain by electroporation, and the transformants were selected on YPD (1\% yeast extract, $2 \%$ Bacto peptone, $2 \%$ glucose) agar plates containing $0.1 \mathrm{mg} / \mathrm{ml}$ Zeocin. A single colony was initially cultured in $1 \mathrm{ml}$ YPD medium containing $0.1 \mathrm{mg} / \mathrm{ml}$ Zeocin for $16 \mathrm{~h}$, which was then transferred to flasks containing $10 \mathrm{ml}$ BMMY (1\% yeast extract, $2 \%$ peptone, $100 \mathrm{mM}$ potassium phosphate, $\mathrm{pH} 6.0,1.34 \%$ yeast nitrogen base, $0.00004 \%$ biotin, $0.5 \% \mathrm{MeOH}$ ) medium and cultured for two days at $30^{\circ} \mathrm{C}$ with shaking at $200 \mathrm{rpm}$ with the addition of $0.05 \mathrm{ml}$ of $0.5 \%$ methanol every $24 \mathrm{~h}$ for the induction of recombinant MPE. To choose the best clones secreting each recombinant MPE, $10 \mu \mathrm{g}$ of total protein in the culture supernatants was separated by $10 \%$ sodium dodecyl sulphate-polyacrylamide gel electrophoresis (SDS-PAGE) and then transferred to a PVDF membrane for a Western blot analysis using an antiMnn14, anti-YlMpo1, or anti-His-tag antibody. Here, anti-Mnn14 and anti-YlMpo1 antibodies were generated using the synthesized peptides of Mnn14 and the denatured YlMpol protein expressed in E. coli, respectively (Koma Biotech, Korea). 
Mannosyl-Phosphorylation Assay Using a DNA Sequencer

In order to compare the enzyme activity of the secreted recombinant MPEs, mannosyl-phosphorylation assays were conducted using $5 \mu \mathrm{g}$ of total protein obtained from the culture supernatants. Unless specifically described in the text, the assay buffer contained $50 \mu \mathrm{l}$ of $50 \mathrm{mM}$ Tris- $\mathrm{HCl}$ (pH 7.5), $10 \mathrm{mM} \mathrm{MnCl}_{2}, 2 \mathrm{mM} \mathrm{GDP-mannose} \mathrm{(donor}$ substrate), $5 \mu \mathrm{M}$ M8-APTS (acceptor substrate), and $0.5 \mathrm{mM}$ deoxymannojirimycin. This reaction was typically performed at $30^{\circ} \mathrm{C}$ for $10 \mathrm{~min}$ and was terminated by boiling. The reaction products were analyzed using a DNA sequencer based on a published protocol [9]. APTS-labeled glycans were loaded onto an ABI 3130 sequencer (Applied Biosystems, USA) equipped with a standard $36 \mathrm{~cm}$ capillary array filled with the POP-7 polyacrylamide linear polymer. The resulting electropherogram was analyzed with the GeneMapper software package (Applied Biosystems). To determine the specific enzyme activity ( $\mathrm{pmol} / \mathrm{min} / \mathrm{mg}$ ), the contents of mannosylphosphorylated glycans were calculated based on the normalized ratio of the corresponding peak area [ $100 \mathrm{x}$ (the areas of mannosyl-phosphorylated glycan peaks)/(total areas of all identified peaks)], as described previously [8].

\section{Purification of rMnn14 $14_{77-935}$}

The P. pastoris harboring pPrMnn $14_{77-935}$ was cultured in the BMMY medium for $48 \mathrm{~h}$ at $30^{\circ} \mathrm{C}$ with shaking at $200 \mathrm{rpm}$, as described in the subsection entitled 'Secretory Expressions in P. pastoris. The culture supernatant was obtained by centrifugation at $8,000 \mathrm{~g}$ for $20 \mathrm{~min}$ and concentrated by the ultracentrifugal filtration using YM50 membrane (Millipore, USA). The concentrate was then dialyzed against a binding buffer $(20 \mathrm{mM}$ Tris- $\mathrm{HCl}, \mathrm{pH}$ 7.5). The dialyzed sample was loaded onto a Q-HP column (GE Healthcare) pre-equilibrated with the binding buffer. After a harsh washing step using more than 10 column volumes of the binding buffer, elution was conducted by a linear gradient of $0-1 \mathrm{M} \mathrm{NaCl}$ in the binding buffer for $50 \mathrm{~min}$. All fractions were collected and analyzed by SDS-PAGE and MPE assays.

Effects of the $\mathrm{pH}$, Temperature, and Metal Ions on the Mannosyl-Phosphorylation Activity of rMnn14 ${ }_{77-935}$

To examine the effects of the $\mathrm{pH}$ on the mannosyl-phosphorylation activity of $\mathrm{rMnn} 14_{77-935}$, the enzyme activity was measured between $\mathrm{pH} 4.0$ and 8.0 using $50 \mathrm{mM}$ sodium acetate buffer ( $\mathrm{pH} 4.0-5.5), 50 \mathrm{mM}$ sodium phosphate buffer ( $\mathrm{pH}$ 6.0-7.5), and $50 \mathrm{mM}$ Tris buffer ( $\mathrm{pH}$ 6.0-8.0). To determine the optimal temperature, the reaction temperature was varied from $25^{\circ} \mathrm{C}$ to $50^{\circ} \mathrm{C}$. To evaluate the effects of metal ions, MPE assays were carried out in the presence of a $10 \mathrm{mM}$ final concentration of various metal ions $\left(\mathrm{MnCl}_{2}, \mathrm{MgCl}_{2}, \mathrm{CaCl}_{2}, \mathrm{FeCl}_{3}, \mathrm{CuSO}_{4}\right.$, or $\mathrm{ZnSO}_{4}$ ) or ethylenediaminetetraacetic acid (EDTA). To find the optimum concentration, the MPE assays were performed with $1,2,5,10$, or $20 \mathrm{mM}$ of $\mathrm{MnCl}_{2}$.

\section{Preparation of rhGAA Containing High-Mannose Type $\mathrm{N}$-Glycans}

The rhGAA-containing high-mannose type $N$-glycans were prepared as described previously [10]. Briefly, they were produced in transgenic rice cell suspension cultures via a treatment with two mannosidase inhibitors (kifunensine and swainsonine) to generate high-mannose type $\mathrm{N}$-glycans ( $\mathrm{Man}_{7-9} \mathrm{GlcNAc}_{2}$ ) instead of plantspecific complex type glycans. His-tagged rhGAA was purified from the suspension cultured media using NiNTA Superflow cartridges (Qiagen, USA).

\section{In Vitro Mannosyl-Phosphorylation of rhGAA}

For in vitro mannosyl-phosphorylation, $5 \mu \mathrm{g}$ of rhGAA was incubated in $50 \mu \mathrm{l}$ of a reaction buffer containing $50 \mathrm{mM}$ Tris- $\mathrm{HCl}$ buffer ( $\mathrm{pH}$ 7.5), $10 \mathrm{mM} \mathrm{MnCl}, 2 \mathrm{mM}$ GDP-mannose, $0.5 \mathrm{mM}$ deoxymannojirimycin, and $\mathrm{rMnn} 14_{77-935}(0.5 \mathrm{mg} / \mathrm{ml})$. After incubation at $30^{\circ} \mathrm{C}$ for $24 \mathrm{~h}$, the reaction was terminated by boiling for $5 \mathrm{~min}$.

\section{$N$-Glycan Analysis of rhGAA}

$\mathrm{N}$-glycans obtained from rhGAA were analyzed using high-performance liquid chromatography (HPLC), as described previously [11]. Briefly, $N$-glycans were released by a PNGase A treatment and purified by solid-phase extraction using graphitized carbon. The purified glycans were labeled with 2-aminobenzamide (2-AA) for fluorescent detection during the HPLC analysis. The 2-AA-labeled glycans were separated on a Shodex Asahipak $\mathrm{NH} 2 \mathrm{P}-504 \mathrm{E}(4.6 \mathrm{~mm} \times 250 \mathrm{~mm})$ column (Showa Denko, Japan) using a Waters Alliance system equipped with a Waters 2475 fluorescence detector (Waters, USA). Solvent A consisted of acetonitrile containing $2 \%$ acetic acid and $1 \%$ tetrahydrofuran. Solvent B consisted of $10 \%$ acetic acid, $6 \%$ triethylamine, and $1 \%$ tetrahydrofuran in water. Elution was carried out with a linear gradient from $90 \% \mathrm{~A}$ and $10 \% \mathrm{~B}$ to $10 \% \mathrm{~A}$ and $90 \% \mathrm{~B}$ at a flow rate of 1 $\mathrm{ml} / \mathrm{min}$ for $70 \mathrm{~min}$ at $50^{\circ} \mathrm{C}$. The fluorescence levels of the AA-labeled glycans were monitored with excitation at $360 \mathrm{~nm}$ and emission at $425 \mathrm{~nm}$. After the HPLC glycan profile analysis, each glycan peak was collected and analyzed using a Microflex MALDI-TOF mass spectrometer (Bruker Daltonik, GmbH, Germany), as described previously [11]. Briefly, 2-AA-labeled glycans were spotted on a MALDI MSP96 polished steel chip (Bruker Daltonik). A matrix solution of 6-Aza-2-thiothymin/2,5-dihydroxybenzoic acid was then added and dried in air. Because mannosyl-phosphorylated glycans have negative charges in their phosphate group, all mass spectra were acquired in a linear negative ion mode.

\section{Results}

\section{Secretory Expressions of Recombinant Mnn14 and YlMpo1 Proteins}

Our previous results showed that YlMpol and Mnn14 have strong mannosyl-phosphorylation activity through complementation experiments in glyco-engineered S. cerevisiae [7, 8]. However, the corresponding in vitro mannosyl-phosphorylation reactions have yet to be shown because they are type II membrane proteins residing in 


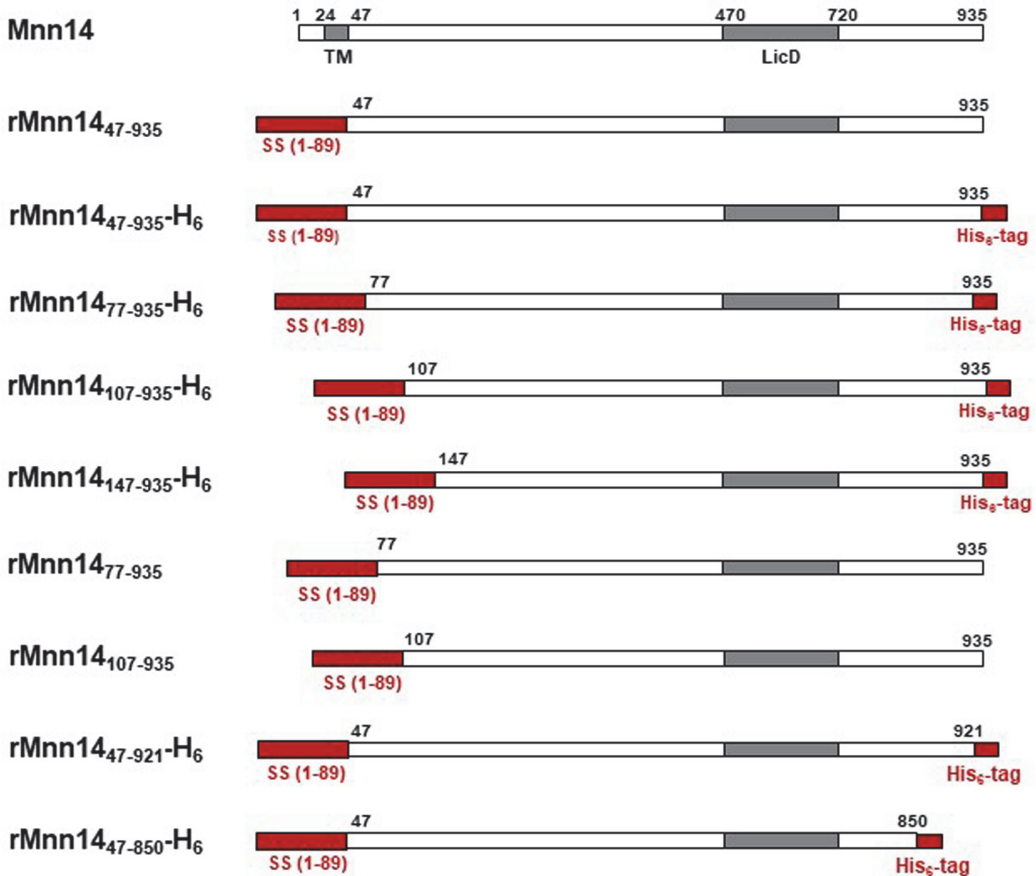

Fig. 2. Schematic representations of various recombinant Mnn14 proteins. Mnn14 is a type II membrane protein that contains a transmembrane (TM) domain (24-46 residue) and LicD domain (470-720 residues) found in the LICD protein family (PF04991), a member of the nucleotidyltransferase fold proteins [8]. Recombinant Mnn14 (rMnn14) proteins were basically designed to be expressed with the mating factor $\alpha$ signal sequence (1-89) instead of the TM domain for secretion, in some cases with additional $\mathrm{N}$-terminal or C-terminal deletions with or without C-terminal His-tag.

the Golgi apparatus, meaning that soluble forms cannot be obtained. The N-terminal transmembrane domains of YlMpol and Mnn14 were replaced with the $\alpha$-mating factor ( $\alpha-M F)$ signal sequence in the pPIZ $\alpha$ A vector for secretory expression in $P$. pastoris. When the constructed pPrMnn14 ${ }_{47-935}$ and pPrYlMpo1 $1_{36-644}$ vectors were transformed to P. pastoris and subjected to Western blot analyses using an anti-Mnn14 antibody and an antiYlMpol antibody, respectively, many clones secreting rMnn14 ${ }_{47-935}$ were found (Fig. S1A), whereas there were no clones secreting rYlMpo $1_{36-644}$ (data not shown). Further, we constructed the vectors for the secretory expression of C-terminal His-tagged rMnn14 $47-935-\mathrm{H}_{6}\left(\mathrm{pPrMnn} 14_{47-935}-\mathrm{H}_{6}\right)$ and $\mathrm{rYlMpo} 1_{36-644}-\mathrm{H}_{6}\left(\mathrm{pPrYlMpo1}_{36-644}-\mathrm{H}_{6}\right)$. Likewise, clones secreting rMnn1 $4_{47-935}-\mathrm{H}_{6}$ were found (Fig. S1B), whereas there were no clones secreting rYlMpo $_{36-644}-\mathrm{H}_{6}$ (data not shown). Therefore, we focused on the secretory expression of recombinant Mnn14 proteins.

Because removal of the $\mathrm{N}$-terminal or $\mathrm{C}$-terminal part was reported to improve the enzyme activity in several glycosyltransferases [12], we constructed a series of vectors expressing recombinant Mnn14 proteins with Nterminal and C-terminal deletions (Fig. 2 and Table S1). Three vectors with $\mathrm{N}$-terminal deletions of 76, 106, or 146 amino acids and the C-terminal addition of His-tag were constructed; pPrMnn14 $4_{77-935}-\mathrm{H}_{6}, \mathrm{pPrMnn} 14_{107-935}-\mathrm{H}_{6}$, and pPrMnn14 ${ }_{147-935}-\mathrm{H}_{6}$ were designed to express rMnn14 $4_{77-935}-\mathrm{H}_{6}, \mathrm{rMnn}_{14} 4_{107-935}-\mathrm{H}_{6}$, and $\mathrm{rMnn}_{14} 4_{147-935}-\mathrm{H}_{6}$, respectively. Two vectors with $\mathrm{C}$-terminal deletions of 14 or 85 amino acids and the addition of His-tag were also constructed: pPrMnn14 $4_{47-921}-\mathrm{H}_{6}$ and pPrMnn14 $4_{47-850}-\mathrm{H}_{6}$ to express $\mathrm{rMnn} 14_{47-921}-\mathrm{H}_{6}$ and $\mathrm{rMnn} 14_{47-850}-\mathrm{H}_{6}$, respectively. P. pastoris clones secreting recombinant Mnn14 with N-terminal deletions ( $\mathrm{rMnn} 14_{77-935}-\mathrm{H}_{6}, \mathrm{rMnn}_{14} 4_{107-935}-\mathrm{H}_{6}$, and rMnn14 $4_{147-935}-\mathrm{H}_{6}$ ) were found (Figs. S1C-S1E), whereas clones secreting recombinant Mnn14 with Cterminal deletions ( $\mathrm{rMnn} 14_{47-921}-\mathrm{H}_{6}$ and $\mathrm{rMnn}_{14} 4_{47-850}-\mathrm{H}_{6}$ ) were not detected (data not shown). These results indicate that the removal of the C-terminal part has a detrimental effect on the secretory expression of Mnn14.

Because the C-terminal part was suggested to be critical for maintaining the protein structure of some glycosyltrnsferases [12], we wondered whether C-terminal His-tag interferes with the enzyme activity of rMnn 14 . In order to test this possibility, two more vectors expressing recombinant Mnn14 proteins without C-terminal His-tag were constructed: pPrMnn14 $4_{77-935}$ and pPrMnn14 ${ }_{107-935}$ to express rMnn14 $4_{77-935}$ and rMnn14 107-935, , respectively (Figs. $2 \mathrm{G}$ and $2 \mathrm{H}$ ).

\section{Comparison of Mannosyl-Phosphorylation Activities}

Clones secreting the largest amounts of rMnn14 variants were selected based on the Western blot analysis (Figs. S1A-S1G). The specific enzyme activities $(\mathrm{pmol} / \mathrm{min} / \mathrm{mg}$ ) for mannosyl-phosphorylation in the culture supernatants of selected clones were then analyzed using a DNA sequencer method. Four recombinant enzymes ( $\mathrm{rMnn} 14_{47-935}, \mathrm{rMnn}_{4} 4_{47-935}-\mathrm{H}_{6}, \mathrm{rMnn} 14_{77-935}-\mathrm{H}_{6}$, and $\mathrm{rMnn14} 4_{77-935}$ ) converted the $\mathrm{Man}_{8} \mathrm{GlcNAc}_{2}$ glycan to the 
A

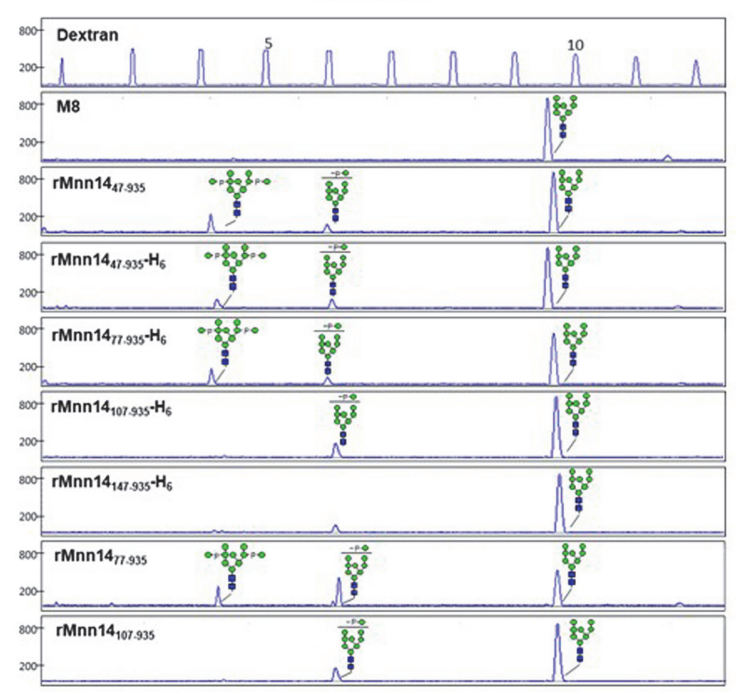

B

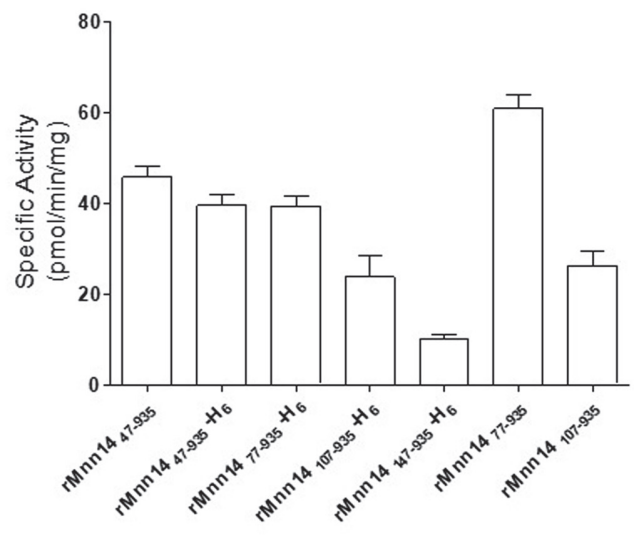

Fig. 3. Mannosyl-phosphorylation activity analysis. (A) An APTS-labeled $\mathrm{Man}_{8} \mathrm{GlcNAc}_{2}$ glycan (M8) was used as a substrate for a mannosyl-phosphorylation analysis using a DNA sequencer. Mono-mannosyl-phosphorylated (ManP$\mathrm{Man}_{8} \mathrm{GlcNAc}_{2}$ ) and/or bis-mannosyl-phosphorylated glycans $\left(\mathrm{Man}_{2} \mathrm{P}_{2}-\mathrm{Man}_{8} \mathrm{GlcNAc}_{2}\right.$ ) are generated by the reaction using $\mathrm{rMnn}_{4} 4_{47-935}, \mathrm{rMnn}_{4} 4_{47-935}-\mathrm{H}_{6}, \mathrm{rMnn} 4_{77-935}-\mathrm{H}_{6}, \mathrm{rMnn14}_{107-935}-\mathrm{H}_{6}, \mathrm{rMnn14} 4_{77-935}$, and rMnn14 $4_{107-935}$ but not rMnn14 $1_{147-935}-\mathrm{H}_{6}$. A dextran reference chromatogram is presented in the first panel to display the glucose units. Symbols are identical to those used in Fig. 1. (B) The specific enzyme activity ( $\mathrm{pmol} / \mathrm{min} / \mathrm{mg}$ ) was determined based on the contents of mannosyl-phosphorylated glycans calculated from the normalized ratio of the corresponding peak area [100 $\times$ (the areas of mannosyl-phosphorylated glycan peaks)/(total areas of all identified peaks)]. The quantified data represent the averages of three replicated experiments with standard deviations.

mono-mannosyl-phosphorylated ( $\mathrm{ManP}_{-} \mathrm{Man}_{8} \mathrm{GlcNAc}_{2}$ ) and bis-mannosyl-phosphorylated forms $\left(\mathrm{Man}_{2} \mathrm{P}_{2}\right.$ $\mathrm{Man}_{8} \mathrm{GlcNAc}_{2}$ ) (Fig. 3A). N-terminal deletion of 106 amino acids ( $\mathrm{rMnn1} 4_{107-935}-\mathrm{H}_{6}$ and $\mathrm{rMnn} 14_{107-935}$ ) led to the loss of the bis-mannosyl-phosphorylated form. The mannosyl-phosphorylation activity nearly disappeared upon $\mathrm{N}$-terminal deletion of 146 amino acids $\left(\mathrm{rMnn} 14_{147-935}-\mathrm{H}_{6}\right)$. Fig. 3B clearly shows that $\mathrm{rMnn} 14_{77-935}$ has the highest level of mannosyl-phosphorylation activity, suggesting that the deletion of the N-terminal 76 amino acids improves the activity of recombinant Mnn14. Notably, each of the rMnn14 ${ }_{47-935}, \mathrm{rMnn} 14_{77-935}$, and rMnn14 ${ }_{107-935}$ samples showed higher activity than the corresponding variant with C-terminal His-tag, suggesting that the Cterminal His-tag interferes with the mannosyl-phosphorylation activity.

Optimal Reaction Conditions of Purified rMnn14 ${ }_{77-935}$ for Mannosyl-Phosphorylation

Because rMnn14 $4_{77-935}$ has the best specific activity, it was purified from the culture supernatant. Briefly, after the concentration and dialysis of the culture supernatant against a binding buffer, $\mathrm{rMnn} 14_{77-935}$ was purified by means of anion-exchange chromatography. The purified rMnn14 $4_{77-935}$ was detected at approximately $100 \mathrm{kDa}$ via the SDS-PAGE (Fig. S1H).

We performed a series of experiments to find the optimal reaction conditions for the mannosyl-phosphorylation activity of purified rMnn14 $4_{77-935}$. To find the best $\mathrm{pH}$, an enzyme assay was performed under different $\mathrm{pH}$ levels ranging from $\mathrm{pH} 4.0$ to $\mathrm{pH} 8.0$. With Tris- $\mathrm{HCl}$ buffer ranging from $\mathrm{pH} 6.0$ to $\mathrm{pH}$ 8.0, the highest activity was observed at $\mathrm{pH} 7.5$. However, the activity level at the same $\mathrm{pH}$ decreased sharply when using sodium phosphate as a buffer. In addition, the activity levels at different $\mathrm{pH}$ values in Tris-HCl buffer were found to be higher than those when sodium acetate or sodium phosphate was used as a buffer (Fig. 4A). It was speculated that the composition of the buffer is also importantly related to the activity of the enzyme. The maximum level of enzyme activity was found at $30^{\circ} \mathrm{C}$, and the activity rapidly decreased after $40^{\circ} \mathrm{C}$ (Fig. $\left.4 \mathrm{~B}\right)$. Among various metal ions $\left(\mathrm{MnCl}_{2}, \mathrm{MgCl}_{2}\right.$, $\mathrm{CaCl}_{2}, \mathrm{FeCl}_{3}, \mathrm{CuSO}_{4}$, and $\mathrm{ZnSO}_{4}$ ) examined at $10 \mathrm{mM}$ with regard to their effect on the enzyme activity of rMnn14 ${ }_{77-935}, \mathrm{MnCl}_{2}$ was found to be best, and its optimal concentration was determined to be $10 \mathrm{mM}$ (Figs. 4C and 4D). Because the metal chelator EDTA completely abolished enzyme activity (data not shown), the existence of metal ions appeared to be essential for mannosyl-phosphorylation activity. Based on these experiments, the optimum reaction condition was set to $50 \mathrm{mM}$ Tris- $\mathrm{HCl}$ buffer $(\mathrm{pH} 7.5), 30^{\circ} \mathrm{C}$, and $10 \mathrm{mM} \mathrm{MnCl}_{2}$.

\section{In Vitro Mannosyl-Phosphorylation of $\mathrm{N}$-Glycans on rhGAA}

Here, rhGAA was selected as a substrate for mannosyl-phosphorylation because it is associated with low therapeutic efficacy stemming from its low M6P content. The M6P content values of rhGAA were reported to be 0.7 to $1.3 \mathrm{~mol} / \mathrm{mol}$ enzyme [13-14]. Myozyme, the rhGAA used for the treatment of Pompe disease, is produced from Chinese hamster ovary $(\mathrm{CHO})$ cells. Out of seven $\mathrm{N}$-glycosylation sites of Myozyme, five sites were occupied 

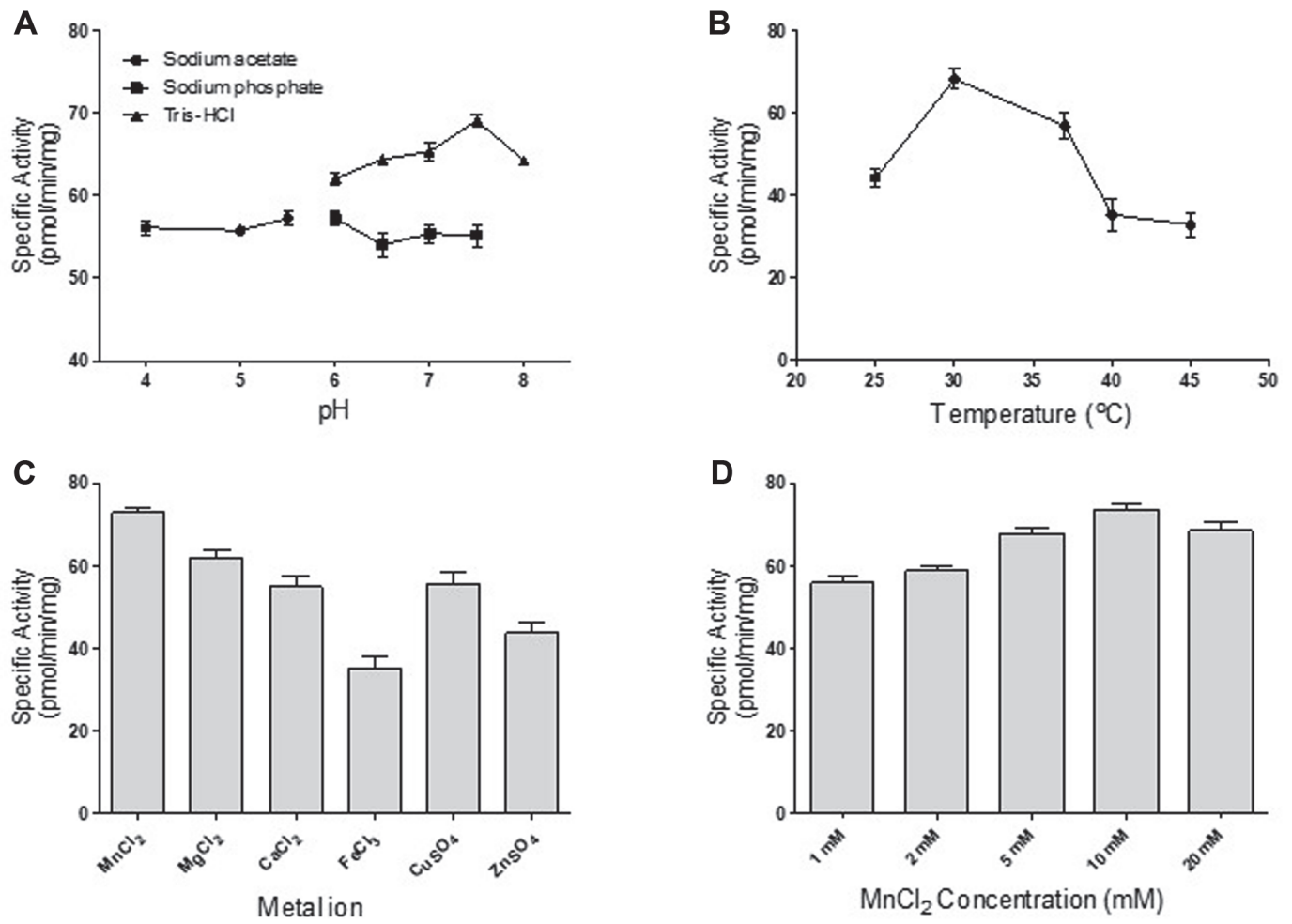

Fig. 4. Optimal reaction conditions of rMnn14 $_{77-935}$ for in vitro mannosyl-phosphorylation. (A) The optimum $\mathrm{pH}$ for the rMnn14 $4_{77-935}$ reaction was determined using three kinds of buffers; $50 \mathrm{mM}$ of sodium acetate $(\mathrm{pH} 4.0-5.5), 50 \mathrm{mM}$ of sodium phosphate ( $\mathrm{pH} 6.0-7.5)$, and $50 \mathrm{mM}$ of Tris- $\mathrm{HCl}(\mathrm{pH} 6.0-8.0)$. (B) The optimum temperature was selected from $25^{\circ} \mathrm{C}$ to $50^{\circ} \mathrm{C}$. (C) The metal ion effect was investigated to find the best metal ion. (D) The optimum concentration of $\mathrm{MnCl}_{2}$ was examined. The quantified data represent the averages of three replicated experiments with standard deviations.

with complex type N-glycans, and only two sites (Asn140 and Asn470) were occupied with M6P glycans [13]. Because MPEs can mannosyl-phosphorylate high-mannose type $N$-glycans, rhGAA containing high-mannose type $\mathrm{N}$-glycans was required for an in vitro mannosyl-phosphorylation experiment. Therefore, we prepared rhGAA containing high-mannose type $N$-glycans using a previously described method [10].

$\mathrm{N}$-glycans of rhGAA, produced in transgenic rice cell suspension cultures containing mannosidase inhibitors, were released and analyzed using HPLC and MALDI-TOF mass spectrometry (Fig. 5). The rhGAA displayed the number 1 peak with a shoulder in the HPLC profile (the upper panel in Fig. 5A), consisting of one major
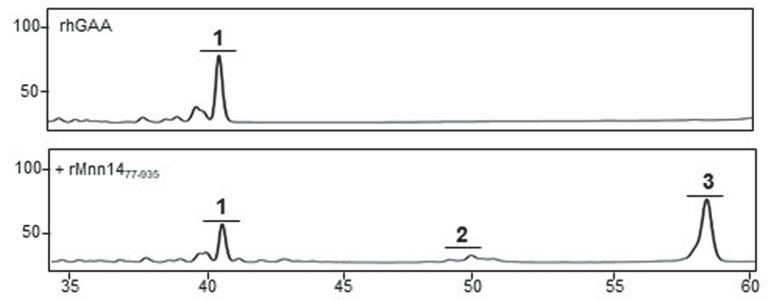

B
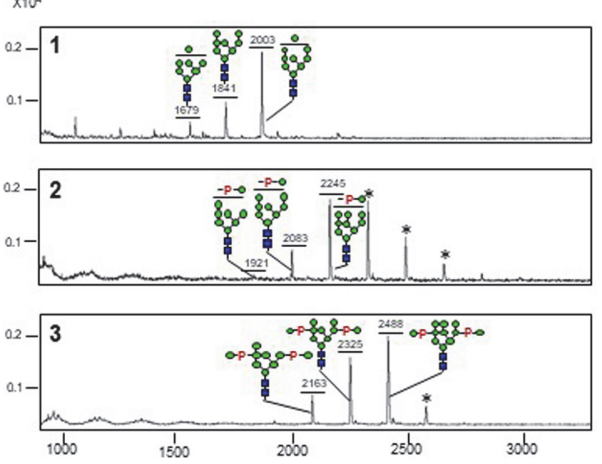

Fig. 5. Generation of mannosyl-phosphorylated glycans on rhGAA by an in vitro reaction using rMnn14 ${ }_{77-935}$. (A) The $\mathrm{N}$-glycans released from rhGAA were analyzed in terms of their HPLC glycan profile (1). After the rMnn14 $77-935$ reaction, the HPLC glycan profile analysis demonstrated the generation of mono-mannosyl-phosphorylated (2) and bismannosyl-phosphorylated glycan peaks (3). (B) The 1-3 peaks in the HPLC profile were collected and analyzed by using MALDI-TOF mass spectrometry. The unidentified peaks are represented by*. Symbols are identical to those used in Fig. 1 . 
$\mathrm{Man}_{9} \mathrm{GlcNAc}_{2}$ and two minor $\mathrm{Man}_{7-8} \mathrm{GlcNAc}_{2}$ glycans (Fig. 5B).

The rhGAA containing $\mathrm{Man}_{7-9} \mathrm{GlCNAc}_{2}$ glycans was used as the substrate for mannosyl-phosphorylation by rMnn $14_{77-935}$. The reaction proceeded in the pre-determined optimal condition for a prolonged time $(\sim 24 \mathrm{~h})$. The resulting HPLC profile demonstrated the generation of the number 2 and number 3 peaks (Fig. 5A), which comprise mono-mannosyl-phosphorylated ( $\mathrm{ManP}-\mathrm{Man}_{7-9} \mathrm{GlcNAc}_{2}$ ) and bis-mannosyl-phosphorylated glycans $\left(\mathrm{Man}_{2} \mathrm{P}_{2}-\mathrm{Man}_{7-9} \mathrm{GlcNAc}_{2}\right)$, respectively. Notably, $74 \%$ of the $\mathrm{Man}_{7-9} \mathrm{GlcNAc}_{2}$ glycans were mannosyl-phosphorylated by the in vitro reaction using $\mathrm{rMnn} 14_{77-935}$ and, moreover, most of the resulting mannosyl-phosphorylated glycans were bis-mannosyl-phosphorylated glycans, which can be converted to bis-phosphorylated M6P glycans with superior lysosomal targeting capability.

\section{Discussion}

M6P glycan, a signal for lysosomal targeting, is the crucial factor determining the therapeutic efficacy of recombinant enzymes used in the treatment of lysosomal storage diseases. Glyco-engineering strategies to increase the M6P glycan contents have been designed to develop "Biobetter" therapeutic enzymes [1]. Specifically, the Callewaert group showed that glyco-engineered Y. lipolytica yeast produced rhGAA containing mannosylphosphorylated glycans, which was converted to M6P glycan using a novel uncapping enzyme [3]. Because our group also developed glyco-engineered $S$. cerevisiae expressing MPEs with strong mannosyl-phosphorylation activity [7], we attempted to produce therapeutic enzymes in these yeasts. However, the resulting secretory expression levels were disappointingly low. As an alternative method, we developed the new strategy to increase the M6P glycan content via the conjugation of glycopeptides containing M6P glycans (M6PgP) derived from glyco-engineered S. cerevisiae [15]. The M6PgP-conjugated rhGAA showed greatly improved lysosomal targeting and the efficient digestion of glycogen accumulated in cells from Pompe disease patients [15]. Although this strategy successfully increased the M6P glycan content, it raised quality control problems because the peptide sequences of M6PgP and their attachment sites to rhGAA cannot be controlled. Therefore, we considered in vitro mannosyl-phosphorylation using an MPE as a direct and straightforward way to increase the M6P glycan content.

The first challenge, when attempting to establish in vitro mannosyl-phosphorylation, was to obtain a soluble recombinant MPE, as MPEs are type II membrane proteins. Because our previous study revealed strong mannosyl-phosphorylation activities of YlMpol and Mnn14 [7-8], they were expressed in P. pastoris which has the superior secretory expression capabilities. P. pastoris clones that secreted Mnn14 with mannosylphosphorylation activity were found, whereas clones that secreted YlMpol were not found. Because most glycosyltransferases contain the cytosolic tail, transmembrane domain, and stem region (CTS) in front of a catalytic domain, their catalytic activities are often affected by the corresponding N-terminal starting site [12]. Therefore, a series of $\mathrm{N}$-terminal-deleted forms were prepared and analyzed, showing that $\mathrm{N}$-terminal 76 amino acid deletion ( $\mathrm{rMnn} 14_{77-935}$ ) improved the activity. Here, $\mathrm{rMnn}_{14} 4_{77-935}$ has the deletions of a cytosolic tail and a transmembrane domain ( 46 amino acids), as well as part of the putative stem region (30 amino acids). This suggests that the 30 amino acids in the stem region interfere with the activity of the soluble recombinant Mnn 14 . Further deletions beyond the 76 amino acids had a negative effect on the mannosyl-phosphorylation activity. Also, our results showed that the addition of C-terminal His-tag decreased the catalytic activity. These results suggest that rMnn $14_{77-935}$ displayed the highest activity because it does not contain unnecessary parts.

The optimum reaction condition for the soluble rMnn14 $4_{77-935}$ was established using a high-mannose type $\mathrm{N}$ glycan $\left(\mathrm{Man}_{8} \mathrm{GlcNAc}_{2}\right)$ as a substrate. Notably, the buffer compound has a much stronger effect on the mannosylphosphorylation activity than $\mathrm{pH}$ itself. The optimized reaction condition was applied for the mannosylphosphorylation of high mannose type $N$-glycans $\left(\mathrm{Man}_{7-9} \mathrm{GlcNAc}_{2}\right.$ ) on rhGAA. Impressively, $74 \%$ of the glycans were bis-mannosyl-phosphorylated. This bis-form can be converted to bis-phosphorylated glycans [3, 15], which have higher affinity for MPR and better lysosomal targeting capabilities [16].

For M6P glycan synthesis, mannosyl-phosphorylation requires the following uncapping reaction to remove the outer mannose (Fig. 1B), while the mammalian GlcNAc-1-phosphotransferase reaction requires the following process to uncover the outer GlcNAc (Fig. 1A). Although the complexities of the entire process of M6P glycan synthesis are comparable, an in vitro reaction using rMnn14 $4_{47-935}$ offers substantial advantages. First, the preparation of rMnn14 ${ }_{47-935}$ is easier than that of GlcNAc-1-phosphotransferase. Because GlcNAc-1-phosphotransferase is a multisubunit enzyme with the $\alpha_{2} \beta_{2} \gamma_{2}$ arrangement, it is highly challenging to prepare a functional recombinant enzyme complex [17-18]. Secondly, MPEs found in yeasts do not appear to recognize specific proteins, whereas GlcNAc-1-phosphotransferase discriminates approximately 60 lysosomal enzymes from many non-lysosomal proteins [18]. It is essential to distinguish the degradation enzymes and confine them in the lysosome to maintain cellular integrity and homeostasis. As GlcNAc-1-phosphotransferase recognizes lysosomal enzymes in a conformation-dependent manner [18], several enzymes, including rhGAA, are poor substrates [17, 19]. In contrast, the minimal requirement for MPE substrates was reported to have at least one $\alpha(1,2)$-linked mannose outside of the mannosyl-phosphorylation site $[7,20]$. They appear to add mannosyl-phosphate to the mannose residues of high-mannose type $N$-glycans and $O$-mannoses on glycoproteins in order to strengthen the cell wall of the yeast [21].

In vitro mannosyl-phosphorylation using rMnn14 ${ }_{77-935}$ is a flexible method to increase the M6P glycan contents of enzymes used as a treatment for lysosomal storage diseases. If therapeutic enzymes containing high-mannose type $N$-glycan are prepared from any production system, such as mammalian or plant cell cultures, they can serve as substrates for rMnn14 $177-935$.

In summary, we generated a soluble recombinant MPE, rMnn14 $4_{77-935}$, with high mannosyl-phosphorylation activity, for the first time. An in vitro reaction using rMnn14 $4_{77-935}$ mannosyl-phosphorylated the glycans on 
rhGAA, which could then be converted to have high M6P glycans contents. These results hold promise with regard to the generation of "Biobetter" therapeutic enzymes with improved lysosomal targeting capabilities.

\section{Acknowledgments}

This work was supported by the Next-Generation BioGreen 21 Program of the Rural Development Administration [PJ013320] and Korea Research Institute of Bioscience and Biotechnology (KRIBB) Research Initiative Program.

\section{Conflict of Interest}

The authors have no financial conflicts of interest to declare.

\section{References}

1. Oh DB. 2015. Glyco-engineering strategies for the development of therapeutic enzymes with improved efficacy for the treatment of lysosomal storage diseases. BMB Rep. 48: 438-444.

2. Chiba Y, Sakuraba H, Kotani M, Kase R, Kobayashi K, Takeuchi M, et al. 2002. Production in yeast of alpha-galactosidase A, a lysosomal enzyme applicable to enzyme replacement therapy for Fabry disease. Glycobiol. 12: 821-828.

3. Tiels P, Baranova E, Piens K, Visscher CD, Pynaert G, Nerinckx W, et al. 2012. A bacterial glycosidase enables mannose-6-phosphate modification and improved cellular uptake of yeast-produced recombinant human lysosomal enzymes. Nat. Biotechol. 30: 1225-1231.

4. Zhu, Y. Zhu Y, Li X, Kyazike J, Zhou Q, Thurberg BL, et al. 2004. Conjugation of mannose 6-phosphate-containing oligosaccharides to acid alpha-glucosidase improves the clearance of glycogen in Pompe mice. J. Biol. Chem. 279: 50336-50341.

5. Zhou Q, Stefano JE, Harrahy J, Finn P, Avila L, Kyazike J, et al. 2011. Strategies for neoglycan conjugation to human acid alphaglucosidase. Bioconjug. Chem. 22: 741-751.

6. Zhou Q, Avila LZ, Konowicz PA, Harrahy J, Finn P, Kim J, et al. 2013. Glycan structure determinants for cation-independent mannose 6-phosphate receptor binding and cellular uptake of a recombinant protein. Bioconjug. Chem. 24: 2025-2035.

7. Gil JY, Park JN, Lee KJ, Kang JY, Kim YH, Kim S, et al. 2015. Increased mannosylphosphorylation of N-glycans by heterologous expression of YlMPO1 in glyco-engineered Saccharomyces cerevisiae for mannose-6-phosphate modification. J. Biotechnol. 206: 66-74.

8. Kim YH, Kang JY, Gil JY, Kim SY, Shin KK, Kang HA, et al. 2017. Abolishment of $N$-glycan mannosylphosphorylation in glycoengineered Saccharomyces cerevisiae by double disruption of MNN4 and MNN14 genes. Appl. Microbiol. Biotechnol. 101:2979-2989.

9. Laroy W, Contreras R, Callewaert N. 2006. Glycome mapping on DNA sequencing equipment. Nat. Protocols 1:397-405.

10. Choi HY, Park H, Hong JK, Kim SD, Kwon JY, You S, et al. 2018. N-glycan remodeling using mannosidase inhibitors to increase highmannose glycans on acid $\alpha$-glucosidase in transgenic rice cell cultures. Sci. Rep. 8: 16130.

11. Kang JY, Kwon O, Gil JY, Oh DB. 2016. Comparison of fluorescent tags for analysis of mannose-6-phosphate glycans. Anal. Biochem. 501: $1-3$

12. Shimma YI, Jigami Y. 2004. Expression of human glycosyltransferase gene in yeast as a tool for enzymatic synthesis of sugar chain. Glycoconj. J. 21: 75-78.

13. McVie-Wylie AJ, Lee KL, Qiu H, Jin X, Do H, Gotschall R, et al. 2008. Biochemical and pharmacological characterization of different recombinant acid alpha-glucosidase preparations evaluated for the treatment of Pompe disease. Mol. Genet. Metab. 94: 448-455.

14. Togawa T, Takada M, Aizawa Y, Tsukimura T, Chiba Y, Sakuraba H. 2014. Comparative study on mannose-6-phosphate residue contents of recombinant lysosomal enzymes. Mol. Genet. Met. 111: 369-373.

15. Kang JY, Shin KK, Kim HH, Min JK, Ji ES, Kim JY, et al. 2018. Lysosomal targeting enhancement by conjugation of glycopeptides containing mannose-6-phosphate glycans derived from glyco-engineered yeast. Sci. Rep. 8: 8730.

16. Zhu Y, Li X, McVie-Wylie A, Jiang C, Thurberg BL, Raben N, et al. 2005. Carbohydrate-remodelled acid alpha-glucosidase with higher affinity for the cation-independent mannose 6-phosphate receptor demonstrates improved delivery to muscles of Pompe mice. Biochem. J. 389: 619-628.

17. Kudo M, Canfield W. 2006. Structural requirements for efficient processing and activation of recombinant human UDP-Nacetylglucosamine: Lysosomal-enzyme- $N$-acetylglucosamine-1-phosphotransferase. J. Biol. Chem. 281: 11761-11768.

18. Meel EV, Lee WS, Liu L, Qian Y, Doray B, Kornfeld S. 2016. Multiple domains of GlcNAc-1-phosphotransferase mediate recognition of lysosomal enzymes. J. Biol. Chem. 291: 8295-8307.

19. Liu L, Lee WS, Doray B, Kornfeld S. 2017. Engineering of GlcNAc-1-phosphotransferase for production of highly phosphorylated lsysosomal enzymes for enzyme replacement therapy. Mol. Thr. (Meth. Clin. Dev.) 5: 59-65.

20. Wang XH, Nakayama KI, Shimma YI, Tanaka A, Jigami Y. 1997. MNN6, a member of the KRE2/MNT1 family, is the gene for mannosylphosphate transfer in Saccharomyces cerevisiae. J. Biol. Chem. 272: 18117-18124.

21. Park JN, Song Y, Cheon SA, Kwon O, Oh DB, Jigami Y, et al. 2011. Essential role of YlMPO1, a novel Yarrowia lipolytica homologue of Saccharomyces cervisiae MNN4, in mannosylphosphorylation of N-and O-linked glycans. Appl. Env. Microbiol. 77: 1187-1195. 